\title{
Adjuvant Chemoradiation for Localized Gastric Adenocarcinoma: An Institutional Experience
}

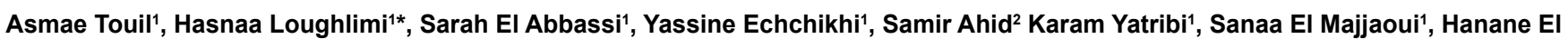
Kacemi ${ }^{1}$, Tayeb Kebdani', and Nourredine Benjafaar ${ }^{1}$

${ }^{1}$ Department of Radiation Oncology, National Institute of Oncology, Mohamed V University in Rabat, Morocco

${ }^{2}$ Department of Public Health, Laboratory of Biostatics, Clinical Research and Epidemiology, Mohamed V University in Rabat, Morocco

\begin{abstract}
Background: Several studies have shown that surgery alone is not enough in the management of early gastric cancer with locoregional relapse in $40 \%$ to $60 \%$. The frequency of relapses makes regional radiotherapy an attractive possibility for adjuvant therapy. The survival benefit of adjuvant chemoradiation over surgery alone was first established by the US Intergroup 0116 study.
\end{abstract}

Patients and methods: Between January 2010 and December 2014, 48 patients with localized gastric adenocarcinoma, managed at radiotherapy department of the national institut of oncology, they underwent adjuvant chemoradiation according the classical MacDonald regimen.

Results: This series consisted of non-metastatic patients, $68.8 \%$ (33) males with a mean age 51 years. $20.8 \%$ (10) of patients had relapses (all distant relapse). 22 (45.8\%) patients died, only $8(16.6 \%)$ patients were lost to follow up. Almost all patients complete full course chemoradiation. The median follow-up duration was 25.4 (15.648) months. The 5 years OS and DFS was $40.8 \%$ and $49 \%$ respectively. Disease stage, operative procedure on primary tumor was an independent prognostic for both 5-year OS and DFS. The pN, surgical margin had a significant impact on OS.

Conclusion: Adjuvant chemo-radiation may be an effective and safe regimen for patients who have undergone gastrectomy with curative intent in locally advanced stomach cancer and did not receive preoperative chemotherapy.

Keywords: Postoperative chemoradiation; Resected gastric cancer; Adenocarcinoma

\section{Background}

Gastric cancer is the second leading cause of cancer related death among men and the fourth among women, and thus represents a significant global health concern [1]. The disease is commonly diagnosed at a locally advanced stage, and surgery remains the main treatment; The overall survival rate of patients who underwent surgery alone is about $45 \%$ at 5 years, that has undergone few changes over the last decades $[2,3]$.

The curative treatment of gastric cancer requires surgical resection in less than $40 \%$ of cases [2,3]. Independent risk factors in the literature are tumor size $(>4 \mathrm{~cm})$, age ( $>70$ years), proximal location, diffuse type of Lauren classification, tumor residue, Deep invasion (T3-T4), and the ratio of involved lymph nodes/total number $(>20 \%)[4,5]$. Locoregional recurrences on the tumor bed, on the anastomosis or in lymph nodes occur in $40 \%$ to $65 \%$ of the patients after resection with curative intent $[6,7]$. The frequency of this relapse makes regional radiotherapy an attractive possibility for adjuvant therapy [8].

Various chemotherapy regimens used to prevent relapse and improve the poor survival rates provide small but statistically significant clinical benefit $[9,10]$. Finally, the intergroup of gastrointestinal cancers (INT-0116) was the first to demonstrate in a phase III trial that concomitant radio-chemotherapy after complete gastric resection improves median relapse-free survival ( 30 vs 19 months, $\mathrm{p}<0.0001$ ) and overall survival ( 36 vs 27 months, $\mathrm{p}<0.01$ ) [11]. Following these results, postoperative radio-chemotherapy according to the Macdonald protocol became the new standard of care [11]. However, much concern remains regarding the toxicity of the regimen. $41 \%$ of patients had grade 3 digestive toxicity and $32 \%$ grade 4 [11]. The objective of our retrospective study was to assess to impact of adjuvant chemoradiation of gastric adenocarcinoma on prognosis.

\section{Materials and Methods}

Between January 2010 and December 2014, we analyzed retrospectively the dada of 48 patients with no metastatic and pathologically confirmed gastric adenocarcinoma staged according to the 6th edition of the American Joint Commission on Cancer (AJCC) 2010. All patients underwent adjuvant chemoradiation after surgery (gastrectomy with lymph node dissection depending on the location of the tumor). One patient underwent hemostatic gastrectomy witch revealed gastric cancer, then lymph node dissection was not performed. R1 and R2 resections were only included if they were denied other treatment. Patients did not receive preoperative chemotherapy. The majority of patients (41 of 48 ) were treated using 5 cycles of 5FU/leucovorin chemotherapy every 28 days. Radiotherapy began with the second cycle (first, fourth, and fifth cycle using 5FU $425 \mathrm{mg} / \mathrm{m}^{2}$ and folinic acid $20 \mathrm{mg} / \mathrm{m}^{2}$ for 5 days; second cycle using 5FU $400 \mathrm{mg} / \mathrm{m}^{2}$ and folinic acid $20 \mathrm{mg} / \mathrm{m}^{2}$ for 4 days, and the third

*Corresponding author: Hasnaa Loughlimi, Department of Radiation Oncology, National Institute of Oncology, Mohamed V University in Rabat Morocco, Tel: 212661696335; E-mail: hasnaa-09fmpm@hotmail.com

Received April 26, 2017; Accepted May 17, 2017; Published May 19, 2017

Citation: Touil A, Loughlimi H, Abbassi SEI, Echchikhi Y, Yatribi SAK, et al. (2017) Adjuvant Chemoradiation for Localized Gastric Adenocarcinoma: An Institutional Experience. J Cancer Sci Ther 9: 433-438. doi: 10.4172/19485956.1000455

Copyright: (C) 2017 Touil AG, et al. This is an open-access article distributed under the terms of the Creative Commons Attribution License, which permits unrestricted use, distribution, and reproduction in any medium, provided the original author and source are credited. 
Citation: Touil A, Loughlimi H, Abbassi SEI, Echchikhi Y, Yatribi SAK, et al. (2017) Adjuvant Chemoradiation for Localized Gastric Adenocarcinoma: An Institutional Experience. J Cancer Sci Ther 9: 433-438. doi: 10.4172/1948-5956.1000455

cycle using the same doses as the second but for 3 days). Seven patients received a capecitabine-based regimen at a dose of $750 \mathrm{mg} / \mathrm{m}^{2}$ to 1000 $\mathrm{mg} / \mathrm{m}^{2}$ twice daily for 14 days, a cycle 28 days before radiotherapy and 2 cycles after. All patients were treated using a 3D conformal radiation technique. The CT simulation was performed in the supine position with arms above their head with slice thickness of $5 \mathrm{~mm}$. The clinical target volume (CTV) included the operative bed, anastomosis with $2 \mathrm{~cm}$ of margin (gastrojejunal, oesophagojejunal) and nodal groups according to the tumor location. The planning target volume (PTV) consisted of the CTV with a $1 \mathrm{~cm}$ margin. The organs at risk were also delineated (kidneys, liver, heart, and spinal cord). A total radiation dose of 45 Gy was delivered in 25 fractions at 1.8 Gy per fraction, five days per week over five weeks. The treatment plan was approved by the radiation oncologist. One patient did not finish the radiotherapy course because of surgical complication (eventration), another one preferred to stop radiation therapy and he was lost of sight. The follow-up was scheduled every 3 months for the first 2 years and every 6 months after 2 years to detect recurrences and treatment complication. No routine endoscopy or CT scans (chest, abdomen, pelvis) were performed only if symptoms. The treatment related toxicities were assessed from patient's records.

The data was analyzed using SPSS version 20.0. Qualitative variables were presented as number and percentages. Quantitative variables were represented as average \pm standard deviation for variables with normal distribution, and as median and interquartile range (IQR) for variables with skewed distributions. The survival rate was analyzed with the Kaplan-Meier method

\section{Results}

Between January 2010 and December 2014, 48 patients with locally advanced gastric cancer received adjuvant concomitant chemo radiation. The patients' characteristics are summarized in Table 1. The mean age was $51 \pm 15$ years with men represented more than two third of patients $68.8 \%$. Only two patients $4.2 \%$ had a history of familial gastric cancer and one third of patients $33.4 \%$ with smoking history. Tumor was located in the upper third of stomach in 26 (54.2\%) patients. Signet ring cells subtype pathology was present in 59\% (28) of patients.

All patients underwent gastrectomy with lymph node dissection (Table 2); eight (16.7\%) patients had positives margins (R1 or R2). Almost three third of patients 73\% (35) underwent D1 or D1.5 Lymph node dissection. Stage II and III represented $44 \%$ and $56 \%$ respectively.

It was noted that $47 \%$ of patients experienced acute gastro-intestinal toxicities (vomiting, nausea, diarrhea, stomatitis, epigastralgia) whereas $33 \%$ of patients experienced acute hematological toxicities.

The median follow-up duration was 25.4 (15.6-48) months. Eighteen patients $(39.5 \%)$ were alive and healthy, 22 (45.8\%) patients were died. All patients $20.8 \%$ [10] with distant relapse were died. No local recurrence was reported. Only $8(16.6 \%)$ patients were lost to follow up. We tried to contact these patients by phone and by sending correspondence letter without resulting from response. The 5 years OS (overall survival) and DFS (disease free survival) was $40.8 \%$ and $49 \%$ respectively (Figures 1 and 2 ). The univariate analysis (Tables 3 and 4) demonstrated that $\mathrm{pN}$ (p: 0.007 and $\mathrm{p}: 0.05$ ) and the operative procedures on primary tumor (p: 0.04 and $\mathrm{p}: 0.01$ ) had a significant impact on OS and DFS respectively. Whereas, the disease stage and the surgical margin were a significant factor for OS (p: 0.001, p: 0.002 respectively) (Figures 3 and 4). Also, the signet ring cells subtype pathology was a non-significant factor for OS (p: 0.08) but on the curve

\begin{tabular}{|c|c|c|}
\hline & Items & $\%(n)$ \\
\hline \multicolumn{2}{|c|}{ Age of diagnostics } & $51 \pm 15$ \\
\hline \multicolumn{3}{|c|}{ Gender } \\
\hline \multirow{4}{*}{ History } & Male & $68.8 \%(33)$ \\
\hline & female & $22.2 \%(11)$ \\
\hline & smoking & $33.4 \%(16)$ \\
\hline & Familial Gastric cancer history & $4.2 \%(2)$ \\
\hline \multicolumn{3}{|c|}{ Mean duration of symptoms: 6 months } \\
\hline \multirow{4}{*}{ Tumor location } & upper third (Antro-pyloric) & $54.2 \%(26)$ \\
\hline & Lower third (Cardia-fundus) & $10.4 \%(5)$ \\
\hline & Middle third & $25 \%(12)$ \\
\hline & Entire stomach & $10.4 \%(5)$ \\
\hline \multirow{5}{*}{$\begin{array}{l}\text { Pathology: } \\
\text { Macroscopic }\end{array}$} & Ulcerating/budding & $62.5 \%(30)$ \\
\hline & Ulcerating/infiltrating & $18.8 \%(9)$ \\
\hline & Ulcerating & $10.4 \%(5)$ \\
\hline & Budding & $6.3 \%(3)$ \\
\hline & Infiltrating & $2.1 \%(1)$ \\
\hline \multirow{3}{*}{ Microscopic } & \multicolumn{2}{|c|}{ Adenocarcinoma } \\
\hline & with signet ring cells & $59.3 \%(28)$ \\
\hline & without signet ring cells & $4.6 \%(16)$ \\
\hline \multirow{5}{*}{ Tumor grading } & Well-differentiated & $6.3 \%(3)$ \\
\hline & Moderately differentiated & $41.7 \%(20)$ \\
\hline & Poorly differentiated & $16.7 \%(8)$ \\
\hline & Undifferentiated & $14.5 \%(7)$ \\
\hline & Not specified & $20.8 \%(10)$ \\
\hline
\end{tabular}

Table 1: Clinical and pathological characteristics of patients.

patient without signet ring cells had better outcome (Figure 6). There was a negative correlation ( $\mathrm{r}$ : -0.07$)$ between the overall survival and the $\mathrm{N}$ ratio (the ratio of metastatic to examined lymph nodes) without reaching the threshold of significance (Figure 5).

The multivariate analysis confirmed that the disease stage as prognostic factor (p: 0.003 OR). The multivariate analysis was not performed for DFS because of the small number of events.

\section{Discussion}

Adjuvant CCR is a standard of care in gastric cancer patients, as this therapeutic modalities combination improved survival. We treated 48 patients, with locally advanced gastric cancer, by primary surgery followed by CCR. The median follow-up duration was 25.4 (15.6-48) months. The 5 years OS and DFS was $40.8 \%$ and $49 \%$ respectively. Disease stage was an independent prognostic factor either for OS or DFS. Although gastrectomy associated with lymph node dissection, depending on tumor location, is the main treatment of gastric cancer; control and survival rate at 5 years remains low, on the order of $20 \%$ to $30 \%$ in T3-T4 patients with positive lymph nodes $[6,12]$. In an attempt to prevent recurrence and increase the cure rate after surgery, multiple studies investigate the role of multimodal treatment approach [12]. Thus, the INT 0116 study published in 2001, was the pivotal randomized trial compared 2 arms: surgery associated or not to combined chemoradiation [11]: At 3 year PFS was $41 \%$ in the surgery arm alone and 50\% in adjuvant CCR arm ( $\mathrm{p}<0.001) ; 3$ years OS was $41 \%$ in the surgery arm alone and $48 \%$ in adjuvant therapy arm $(p=0.005)$ [11]. The update of the intergroup trial was confirmed the OS benefit at 10 years [13]. These results have been confirmed by other authors $[12,14,15]$. In our study, all patients received adjuvant CCR, the 5 -year OS was $40.8 \%$ and 5 year DFS was $49 \%$. These results are comparable to literature. 
Citation: Touil A, Loughlimi H, Abbassi SEI, Echchikhi Y, Yatribi SAK, et al. (2017) Adjuvant Chemoradiation for Localized Gastric Adenocarcinoma: An Institutional Experience. J Cancer Sci Ther 9: 433-438. doi: 10.4172/1948-5956.1000455

\begin{tabular}{|c|c|c|}
\hline \multicolumn{2}{|c|}{ Items } & $\%(n)$ \\
\hline \multirow{5}{*}{$\begin{array}{l}\text { Operative procedures } \\
\text { Primary tumor }\end{array}$} & Total Gastrectomy & $41.7 \%(20)$ \\
\hline & Subtotal Gastrectomy & $39.6 \%(19)$ \\
\hline & Total extented Gastrectomy & $12.5 \%(6)$ \\
\hline & Two-third Gastrectomy & $2.1 \%(1)$ \\
\hline & Oesophagogastrectomy & $4.2 \%(2)$ \\
\hline \multirow{5}{*}{ Lymph nodes dissection type } & D0 & $14.6 \%(7)$ \\
\hline & D1 & $39.5 \%(19)$ \\
\hline & D1.5 & $35.4 \%(17)$ \\
\hline & D2 & $8.3 \%(4)$ \\
\hline & Not performed & $2 \%(1)$ \\
\hline \multirow{3}{*}{ pT } & pT2 & $4.2 \%(2)$ \\
\hline & pT3 & $79 \%(38)$ \\
\hline & pT4 & $16.6 \%(8)$ \\
\hline \multirow{3}{*}{ Margins } & Ro & $83.3 \%(40)$ \\
\hline & $\mathrm{R} 1$ & $10.4 \%(5)$ \\
\hline & $\mathrm{R} 2$ & $6.3 \%(3)$ \\
\hline \multirow{5}{*}{$\mathrm{pN}$} & No & $14.8 \%(7)$ \\
\hline & N1 & $25.5 \%(12)$ \\
\hline & N2 & $27.6 \%(13)$ \\
\hline & N3a & $21.2 \%(10)$ \\
\hline & N3b & $10.6 \%(5)$ \\
\hline \multirow{5}{*}{ Stage } & IIA & $17 \%(8)$ \\
\hline & IIB & $27 \%(13)$ \\
\hline & IIIA & $17 \%(8)$ \\
\hline & IIIB & $31.9 \%(15)$ \\
\hline & IIIC & $6.4 \%(3)$ \\
\hline \multirow{2}{*}{ LVE } & Positif & $54.3 \%(25)$ \\
\hline & Negatif & $45.6 \%(21)$ \\
\hline \multirow{2}{*}{ N Ratio } & $<20 \%$ & $36.9 \%(17)$ \\
\hline & $>20 \%$ & $63 \%(29)$ \\
\hline \multirow{4}{*}{ Chemotherapy (CMT) } & \multicolumn{2}{|c|}{ CMT regimens } \\
\hline & $5 \mathrm{FU}$ & $85.4 \%(41)$ \\
\hline & Capecitabine & $14.5 \%(7)$ \\
\hline & Number of cures & $4.64 \pm 0.67$ \\
\hline
\end{tabular}

Table 2: Pathologic and therapeutic characteristics of patients.

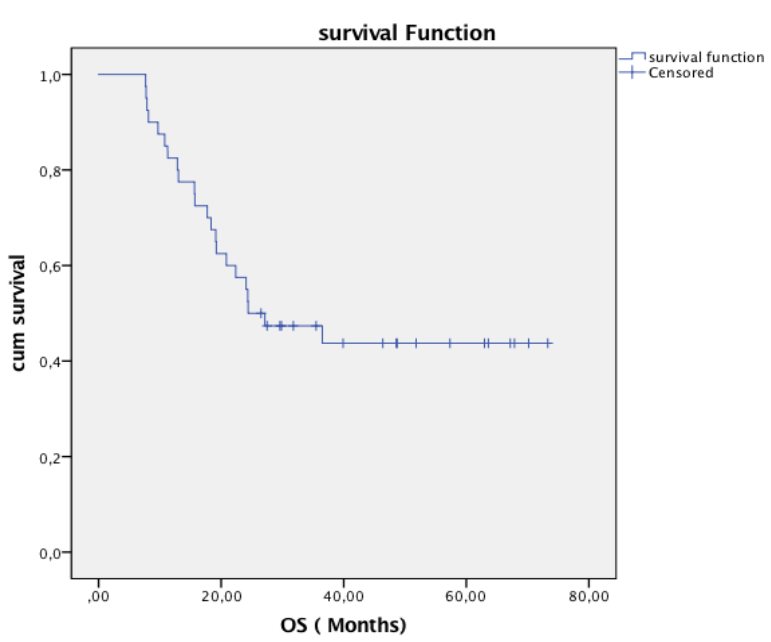

Figure 1: Overall survival curve.

Gastric cancer is mostly diagnosed at a locally advanced stage [1]. $56 \%$ of patients in this study were stage III (Figure 3). $95.8 \%$ of patients had T3-T4 tumor versus $69 \%$ in INT-0116 trial, even in several retrospectives series more than $75 \%$ of patients was T3T4 $[8,16-18]$. In our study, $85 \%$ of patients had lymph nodes involvement as like in INT-0116 [11], similar results were cited in literature [8,12,16-18].

The number of involved lymph nodes has a significant impact on survival [19]. It has been demonstrated a correlation between the number of positive lymph node and the OS, which was lower if more than 16 nodes is involved [20] Thus a high $\mathrm{N}$ is an adverse factor [20]. Also, The $\mathrm{N}$ ratio was retained as an independent prognostic factor both in patients with D1 and D2 lymphadenectomy [21], So, correlation of the two, the number of lymph node metastases and lymph node ratio, is

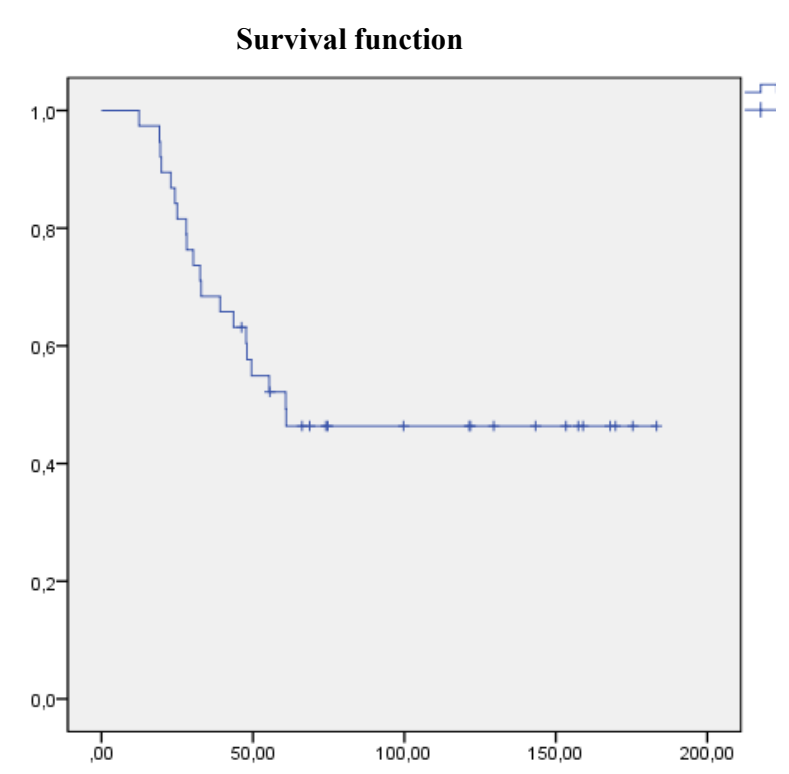

Figure 2: Disease free survival curve.

\begin{tabular}{|c|c|c|c|c|c|c|}
\hline & \multicolumn{3}{|c|}{ OS } & \multicolumn{3}{c|}{ DFS } \\
\cline { 2 - 7 } & OR & $\mathbf{9 5 \%} \mathbf{C l}$ & $\mathbf{p}$ & $\mathbf{O R}$ & $\mathbf{9 5 \%} \mathbf{C l}$ & $\mathbf{p}$ \\
\hline Tumor location & 1.09 & $0.49-2.42$ & 0.82 & 1.07 & $0.42-2.68$ & 0.88 \\
\hline stage & 4.51 & $1.84-11.09$ & $\mathbf{0 . 0 0 1}$ & 1.6 & $0.78-3.28$ & 0.1 \\
\hline Age & 0.99 & $0.95-1.03$ & 0.72 & 0.98 & $0.94-1.03$ & 0.53 \\
\hline pN & 2.79 & $1.32-5.91$ & $\mathbf{0 . 0 0 7}$ & 2.09 & $0.99-4.4$ & $\mathbf{0 . 0 5}$ \\
\hline Surgical margins & - & - & $\mathbf{0 . 0 0 2}$ & 5.00 & $0.92-26.9$ & 0.06 \\
\hline LN dissection type & 1.04 & $0.56-1.9$ & 0.89 & 0.84 & $0.40-1.73$ & 0.63 \\
\hline N ratio & 0.66 & $0.06-6.74$ & 0.72 & 4.13 & $0.30-56.15$ & 0.3 \\
\hline Pathology & - & - & 0.08 & & & \\
\hline $\begin{array}{c}\text { Operative procedures on } \\
\text { primary tumor }\end{array}$ & 2.59 & $1.04-6.41$ & $\mathbf{0 . 0 4}$ & 1.51 & -3.79 & $\mathbf{0 . 0 1}$ \\
\hline $\begin{array}{c}\text { CMT Regimen } \\
\text { Number Of CMT Cures }\end{array}$ & 0.47 & $0.09-2.49$ & 0.37 & 1.37 & $0.21-8.66$ & 0.73 \\
\hline & 1.28 & $0.55-2.96$ & 0.56 & 1.04 & $0.39-2.76$ & 0.93 \\
\hline
\end{tabular}

Table 3: Univariate analysis for parameters influencing OS and DFS

\begin{tabular}{|c|c|c|}
\hline Gastrointestinal & Chemotherapy & Combined chemoradiation \\
\hline Nausea/vomiting & $25(52 \%)$ & $19(39 \%)$ \\
\hline Epigastralgia & $12(25 \%)$ & $23(47 \%)$ \\
\hline Mucositis & $13(27 \%)$ & $7(14 \%)$ \\
\hline Diarrhea & $21(43 \%)$ & $23(47 \%)$ \\
\hline \multicolumn{3}{|c|}{ Hematological } \\
\hline Neutropenia & $27(56 \%)$ & $16(33 \%)$ \\
\hline Anemia & $22(45 \%)$ & $11(22 \%)$ \\
\hline
\end{tabular}

Table 4: Acute toxicities during chemoradiotherapy. 


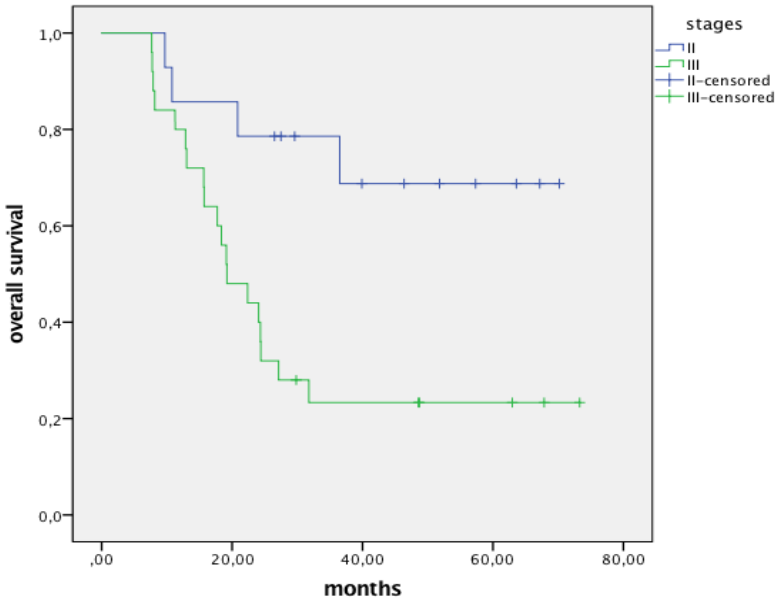

Figure 3: Overall survival by stages.

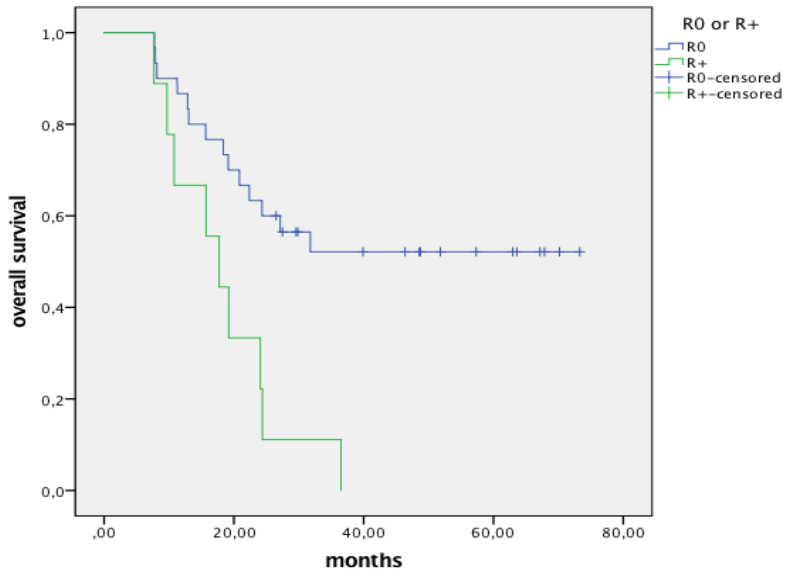

Figure 4: Overall survival by surgical margins.

obvious [22]. In our study, the pN influenced the OS and the DFS, and there was a negative correlation between the $\mathrm{OS}$ and the $\mathrm{N}$ ratio without reaching the threshold of significance (Figure 5). The extent of lymph node dissection is controversial $[12,19]$. It has been suggested a survival benefit of the adjuvant chemoradiation therapy in D2-resected gastric cancer patients [12]. Four major randomized trials, investigated the extent of lymphadenectomy, show no survival advantage on outcome, even the postoperative mortality and morbidity among patients with D2 dissection is higher in patients from European descent [23-26]. In our study lymph node dissection extent showed no benefit neither in DFS nor in OS. Two controlled studies compared total gastrectomy to subtotal gastrectomy; There was no difference in mortality rate, and the 5-year OS was the same in both arms (48\%) [27,28]. Unlike, in our study, there was a difference statistically significant in surgical procedure in 5 -year OS $(\mathrm{p}=04)$. This can be explained that patients undergoing total gastrectomy probably reflects larger tumors and unfavorable proximal lesions that prompt such a procedure. A positive resection margin was shown to be an independent adverse factor for survival in several surgical series before the advent of adjuvant CRT regarding patients who have had a microscopically incomplete resection, a retrospective comparison of the Dutch D1D2 trial has suggested significant improvements in OS and local recurrence rates with use of CRT after an R1 resection [29,30]. In our study, the surgical margin alter significantly outcome (Figure 4). In the INT-0116 study, only $181(64 \%)$ completed treatment due to Grade 3-4 toxicities in $41 \%$ and $32 \%$ patients [11]. Similarly, other studies reported high toxicities grade 3-4 [31,32]. In our study the CCR was well tolerated thus almost all patient completed treatment. Also, others retrospectives series reported less grade 3-4 toxicities [33-35]. Maybe the use of conventional RT was the cause of relatively higher rates of toxicity in this study. The other risk factors (age, tumor size, tumor grade, LVE) known for their negative impact on survival were not found; though patient without signet ring cells subtype pathology had better outcome on the curve without reaching the threshold of significance (Figure 6). This can be explained by the small number of patients in our study. The main limitations of this study were the relatively small size, because of the majority of patients came from other structures, and the lack of reporting of data on toxicities grading associated with concomitant radio-chemotherapy.

\section{Conclusion}

The unfavorable prognosis of locally advanced stomach cancers justified numerous trials evaluating adjuvant treatments.

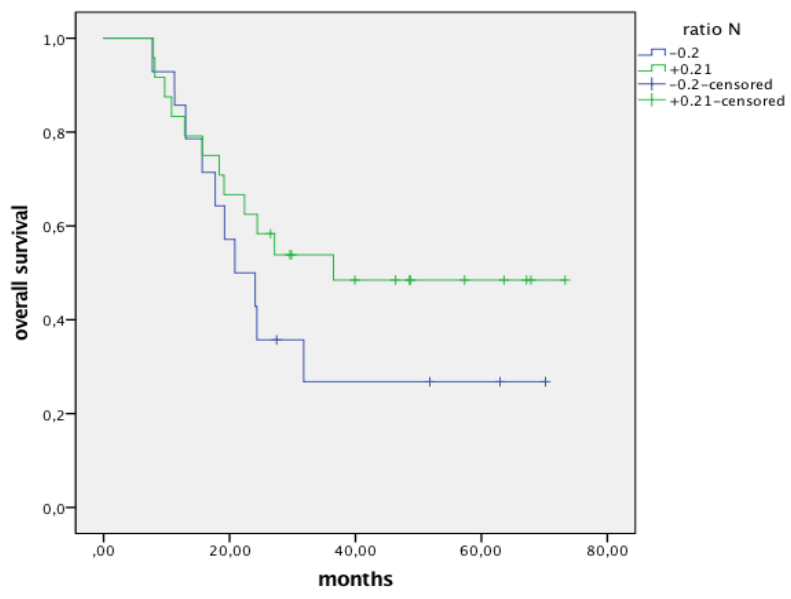

Figure 5: Overall survival by $\mathrm{N}$ ratio.

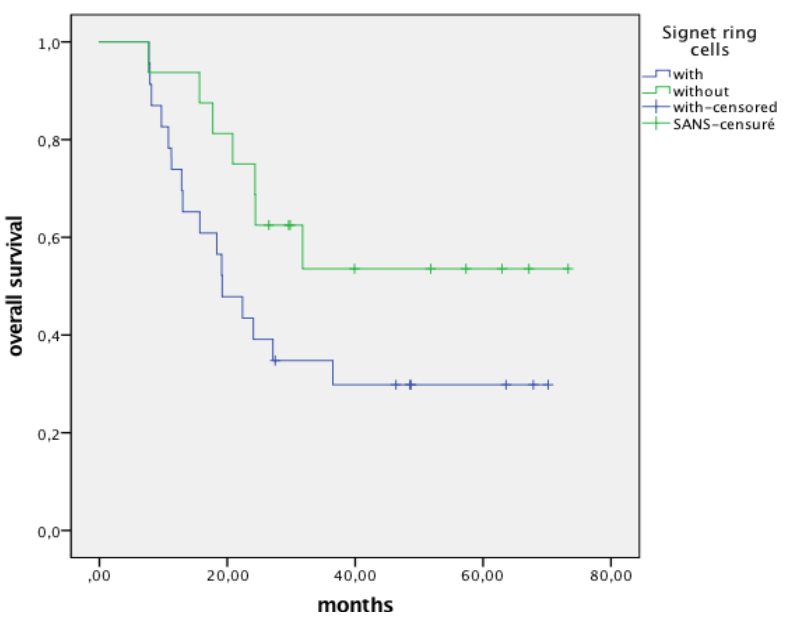

Figure 6: Overall survival by pathology. 
Citation: Touil A, Loughlimi H, Abbassi SEI, Echchikhi Y, Yatribi SAK, et al. (2017) Adjuvant Chemoradiation for Localized Gastric Adenocarcinoma: An Institutional Experience. J Cancer Sci Ther 9: 433-438. doi: 10.4172/1948-5956.1000455

Chemoradiation was evaluated in a large controlled trial which showed a significant improvement in overall survival and recurrence-free survival after gastrectomy for localized stage cancers. Although our study has a low strength, this protocol is feasible in our institute with a fairly good tolerance, and without interruption of treatment.

\section{Competing Interests}

The authors declare that they have no competing interests.

\section{Funding}

Special thanks are due to the Faculty of Medicine and Pharmacy of Rabat; the source(s) of funding for all authors

\section{Acknowledgement}

All the authors are thankful for providing the necessary facilities for the preparation the manuscript.

\section{Ethics Approval and Consent to Participate}

Not applicable

\section{Availability of Data and Material}

Data sharing not applicable to this article as no datasets were generated or analysed during the current study.

\section{References}

1. Garcia M, Ward EM, Center MM, Hao Y, Siegel RL, et al. (2016) Global cancer facts and figures.

2. Dupont JB Jr, Lee JR, Burton GR, Cohn I Jr (1978) Adenocarcinoma of the stomach: Review of 1,497 cases. Cancer 41: 941-947.

3. Hundahl SA, Phillips JL, Menck HR (2000) The National Cancer Data Base (5thedn). American Joint Committee on Cancer staging proximal disease, and the "different disease" hypothesis. Cancer 88: 921-932.

4. Kim JP, Kim YW, Yang HG, Noh DY (1994) Significant prognostic factors by multivariate analysis of 3926 gastric cancer patients. World J Surg 18: 872-877.

5. Kajiyama Y, Tsurumaru M, Udagawa H, Tsutsumi K, Kinoshita Y, et al. (1997) Prognostic factors in adenocarcinoma of the gastric cardia: Pathologic stage analysis and multivariate regression analysis. J Clin Oncol 15: 2015-2021.

6. Landry J, Tepper JE, Wood WC, Moulton EO, Koerner F, et al. (1990) Patterns of failure following curative resection of gastric cancer. Int J Radiat Oncol Biol Phys 191: 1357-1362.

7. Gunderson LL (2002) Gastric cancer-patterns of relapses aftersurgicalresection. Semin Radiat Oncol 12: 150-161.

8. Kundel Y, Purim O, Idelevich E (2011) Postoperative chemoradiation for resected gastric cancer - is the Macdonald Regimen Tolerable? a retrospective multi-institutional study. Radiat Oncol 6: 127

9. Earle CC, Maroun JA (1999) Adjuvant chemotherapy after curative resection for gastric cancer in non-Asian patients: revisiting a meta-analysis of randomized trials. Eur J Cancer 35: 1059-1064.

10. 10.Mari E, Floriani I, Tinazzi A, Buda A, Belfiglio M, et al. (2000) Efficacy of adjuvant chemotherapy after curative resection for gastric cancer: a metaanalysis of published randomized trials. A study of the GISCAD (Gruppo Italiano per lo Studio dei Carcinomi dell'Apparato Digerente). Ann Oncol 11: 837-843.

11. Macdonald JS, Smalley SR, Benedetti J, Hundahl SA, Estes NC, et al. (2001) Chemoradiotherapy after surgery compared with surgery alone for adenocarcinoma of the stomach or gastroesophageal junction. $\mathrm{N}$ Engl J Med 345: 725-730.

12. Kim S, Lim DH, Lee J, Kang WK, MacDonald JS, et al. (2005) An observational study suggesting clinical benefit for adjuvant postoperative chemoradiation in a population of over 500 cases after gastric resection with D2 nodal dissection for adeno-carcinoma of the stomach. Int J Radiat Oncol Biol Phys 63: 1279-1285.

13. Macdonald JS, Smalley S, Benedetti J, Hundahl SA, et al. (2001) Postoperative combined radiation and chemotherapy improves disease-free survival (DFS) and overall survival (OS) in resected adenocarcinoma of the stomach and GE junction. Results of Intergroup Study INT-0116 (SWOG 9008). Eur J Cancer 37: S10.

14. Bora H, Unsal D, Akmansu M (2004) Results of chemoirradiation after curative resection of locally advanced gastric cancer. Int J Clin Pract 58: 451-456.

15. Park SH, Kim DY, Heo JS (2003) Post-operative chemoradiotherapy for gastric cancer. Ann Oncol 14: 1373-1377.

16. Yoney A, Bati Y, Isikli L, Unsal M (2011) Post-operative chemoradiation in patients with localized gastric adenocarcinoma: Single center experience. Indian J Cancer 48: 24-30.

17. Hughes BG, Yip D, Chao M, Gibbs P (2004) Audit of post-operative chemoradiotherapy as adjuvant therapy for resected gastroesophageal adenocarcinoma: An Australian multicentre experience. ANZ J Surg 4: 951-956.

18. Aftimos PG, Nasr EA, Nasr DI, Noun RJ, Nasr FL, et al. (2010) Adjuvant chemoradiation for gastric adenocarcinoma: An institutional experience. Radiat Oncol 5: 50

19. Brian G. Czito, Manisha Palta, and Christopher G. Willett in radiation oncology (6thedn). 7337.

20. Marchet A, Mocellin S, Ambrosi A, Morgagni P, Garcea D, et al. (2007) Italian Research Group for Gastric Cancer (IRGGC): The ratio between metastatic and examined lymphnodes ( $\mathrm{N}$ ratio) is an independent prognostic factor in gastric cancer regardless of the type of lymphadenectomy: Results from an Italian multicentric study in 1853 patients. Ann Surg 245: 543-552.

21. Marchet A, Mocellin S, Ambrosi A (2007) The ratio between metastatic and examined lymph nodes (N Ratio) is an independent prognostic factor in gastric cancer regardless of the type of lymphadenectomy. Ann Surg 245: 543-552.

22. Yamashita K, Hosoda K, Akira E, Masahiko W (2016) Lymph node ratio as a novel and simple prognostic factor in advanced gastric cancer. Eur $\mathrm{J}$ Surg Oncol 42: 1253-1260.

23. Bonenkamp JJ, Songun I, Hermans J, Sasako M, Welvaart K et al. (1995) Randomized comparison of morbidity after D1 and D2 dissection for gastric cancer in 996 Dutch patients. Lancet 345: 745-748.

24. Cuschieri A, Weeden S, Fielding J, Bancewicz J, Craven J, et al. (1999) Patien survival after D1 and D2 resections for gastric cancer: Long-term results of the MRC randomized surgical trial. Br J Cancer 79: 1522-1530.

25. Sasako M, Sano T, Yamamoto S (2008) D2 lymphadenectomy alone or with para-aortic nodal dissection for gastric cancer. N Engl J Med 359: 453-462

26. Degiuli M, Sasako M, Ponti A (2010) Morbidity and mortality in the Italian Gastric Cancer Study Group randomized clinical trial of D1 versus D2 resection for gastric cancer. Br J surg 97: 643-649.

27. Gouzi JL, Huguier M, Fagniez PL, Launois B, Flamant Y, et al. (1989) Tota versus subtotal gastrectomy for adenocarcinoma of the gastric antrum: a french prospective controlledstudy. Ann Surg 209: 162.

28. Bozzetti F, Marubini E, Bonfanti G, Miceli R, Piano C, et al. (1999) Subtotal versus total gastrectomy for gastric cancer: Five-year survival rates in a multicenter randomized Italian trial. Italian Gastrointestinal Tumor Study Group. Ann Surg 230: 170-178.

29. Dikken JL, Jansen EP, Cats A (2010) Impact of the extent of surgery and postoperative chemoradiotherapy on recurrence patterns in gastric cancer. $\mathrm{J}$ Clin Oncol 28: 2430-2436.

30. Stiekema J, Trip AK, Jansen EP (2014) The prognostic significance of an R1 resection in gastric cancer patients treated with adjuvant chemoradiotherapy. Ann Surg Oncol 21: 1107-1114.

31. Di Costanzo F, Gasperoni S, Manzione L (2008) Adjuvant chemotherapy in completely resected gastric cancer: a randomized phase III trial conducted by GOIRC. J Natl Cancer Inst 100: 388-398.

32. Leong T, Joon DL, Willis D (2010) Adjuvant chemoradiation for gastric cance using epirubicin, cisplatin and 5-flourouracil before and after three dimensional 
Citation: Touil A, Loughlimi H, Abbassi SEl, Echchikhi Y, Yatribi SAK, et al. (2017) Adjuvant Chemoradiation for Localized Gastric Adenocarcinoma: An Institutional Experience. J Cancer Sci Ther 9: 433-438. doi: 10.4172/1948-5956.1000455

conformal radiotherapy with concurrent infusional 5-fluorouracil a multicenter study of the Trans-Tasman Radiation Oncology Group. Int J Radiat Oncol Biol Phys 79: 690-695.

33. Hughes BG, Yip D, Chao M, Gibbs P, Carroll S, (2004) Audit of post-operative chemoradiotherapy as adjuvant therapy for resected gastroesophageal adenocarcinoma: An Australian multicentre experience. ANZ J Surg 74: 951-956.
34. Tsang WK, Leung SF, Chiu SK, Yeung WW, Ng EK, et al. (2007) Adjuvant chemoradiation for gastric cancer: Experience in the Chinese population. Clin Oncol (R Coll Radiol) 19: 333-340.

35. Aftimos PG, Nasr EA, Nasr DI, Noun RJ, Nasr FL, et al. (2010) Adjuvant chemoradiation for gastric adenocarcinoma: An institutional experience. Radiat Oncol 5: 50 . 